\title{
Projeto de leitura e escrita na formação continuada de professores do ensino fundamental I.
}

\author{
Sergio Vale da Paixão \\ (UNESP/Assis/IFPR/Jacarezinho)
}

\begin{abstract}
Resumo
A falta de diálogo e de conhecimentos sobre possibilidades de trabalho com o texto na sala de aula, à luz das recentes teorias trazidas pelos Estudos da Linguagem, favorecem práticas pedagógicas convencionais desprovidas de sentido para o leitor/escritor na escola. Nesse sentido, propomos uma conversa neste texto, no intuito de socializar um trabalho que realizamos há algum tempo em uma secretaria de educação municipal, na qual professores do ensino fundamental I estão mudando seu modo de planejar aulas e, principalmente, de trabalhar com o texto na escola. Tais mudanças são frutos de encontros de formação continuada via projetos, em que o texto e as recentes teorias são objetos de estudo, uma vez que a carga horária dispensada para a disciplina de Metodologia de Ensino de Língua Portuguesa não foi suficiente na formação inicial deste grupo de professores, segundo relato das próprias educadoras participantes.
\end{abstract}

Palavras-chave: Leitura e escrita; formação continuada; projetos escolares.

\begin{abstract}
The lack of dialogue and knowledge about possibilities for working with the text in the classroom, an issue that has been brought to light in theories addressed in Language Studies, helps to perpetuate conventional teaching practices that are meaningless to the reader / writer in school. In this sense, we present a discussion, in order to socialize the work we have been doing for some time in a municipal education department in which the elementary school teachers are changing their way of planning classes, and especially of working with the text in school. These changes are the result of continuing education meetings through projects in which the text and recent theories are the objects of study. One point of consideration is that the time given to the discipline of Portuguese Language Teaching Methodology was insufficient in the initial coursework of this group of teachers, according to reports of the participating educators.
\end{abstract}

Key words: Reading and writing; continuing education; school projects.

\section{INTRODUÇÃO}

Em tempos em que inovações tecnológicas têm sido incorporadas ao trabalho educativo e no qual a reflexão acerca da digitalização e virtualização do ensino e do uso de novas ferramentas didáticas, na era dos letramentos digitais, estão sendo utilizadas no contexto educacional, ainda é comum nos depararmos com discursos acerca da não 
participação dos alunos em atividades propostas pelos educadores nas instituições de ensino. Tais discursos criticam de modo acentuado a falta de envolvimento discente, mesmo quando são propostas "aulas diferentes" e são usadas certas tecnologias para "agradar" ou deixar a aula mais "legal" e "interessante", fazendo uso de expressões utilizadas frequentemente pelos professores.

Questionamos com frequência em encontros de formação inicial e continuada de educadores, certos posicionamentos em relação a essa "não participação" dos alunos nas atividades. Apontamentos clássicos que há tempos estão presentes nos diálogos de sala de professores e em reuniões pedagógicas: "Como avalio a não participação e a aprendizagem dos alunos?" "O que é uma aula legal e interessante?" e quando o assunto é a leitura e produção de textos, tema que aqui nos propomos dialogar, é bastante comum dizer que os alunos de hoje não leem mais e não escrevem com a qualidade de "outros tempos". E, em tempos de metodologias que utilizam recursos tecnológicos de ensino, questionamos: uma aula "legal”, “divertida" em que estão presentes vídeos, sons, imagens e redes sociais resulta em aprendizagem, verdadeiramente? Ou ainda, quais são as motivações que estão presentes nessa construção de conhecimento?

Tais questionamentos são muito relevantes para refletirmos a formação do educador e analisarmos o verdadeiro papel da formação inicial e continuada e metodologias utilizadas nos momentos organizados para reuniões docentes durante o ano letivo. Interessa-nos refletir, assim como se faz nos discursos dos educadores a respeito da formação do aluno, o processo de construção do conhecimento "docente", daquele que, assim como os alunos, necessita de envolvimento, interação, diálogo e emoção para aprender. É nesse sentido que propomos uma comparação no que diz respeito à formação do aluno e do educador, no intuito de perceber e problematizar a formação de ambos, uma vez que o resultado esperado, independente do indivíduo em questão, é a aprendizagem.

\section{REPENSANDO A FORMAÇÃO CONTINUADA}

É comum que se atribua o termo "formação continuada" ou "formação pedagógica" aos encontros relâmpagos que ocorrem nas semanas pedagógicas, em datas específicas para esse fim. Palestras de poucas horas, recheadas de brincadeiras e humor, conhecidas como palestras motivacionais têm sido habitual em formações como essas. Não desmerecemos a iniciativa, ao contrário, valorizamos esse tipo de trabalho por 
considerarmos que a emoção e a afetividade, muito presentes nessas atividades, são essenciais para um revigoramento das ações e reflexões acerca da prática pedagógica, porém questionamos práticas que não se preocupam verdadeiramente com a aprendizagem do educador. Um trabalho descontraído, dinâmico, didático é sempre muito bem-vindo, quando a proposta é, no mínimo, refletir sobre o processo de formação e, principalmente, encontrar soluções e oportunidades para uma evolução, um progresso naquilo que se configura uma fragilidade na prática docente.

O interessante é o professor questionar seu próprio processo de formação: o que me move a aprender? Quais são as minhas dificuldades de aprendizagem? Como são, para mim, as aulas "legais", "interessantes" quando me coloco no papel de aprendiz? Será que aprendo com vídeos, com humor, com som, com a palestra motivacional? Tais práticas me levam a ser um educador melhor naquilo que talvez seja minha maior dificuldade em sala de aula? Quais são as minhas experiências como professor e em que elas podem colaborar para uma nova configuração de escola? Como estou lidando com o sujeito cognoscente, com o sujeito da experiência em minha prática pedagógica, visto como um ser envolvido em histórias, culturas e inserções sociais.

No dizer de Larrosa (2011, p.8),

O sujeito da experiência é como um território de passagem, como uma superfície de sensibilidade em que algo passa e que "isso que me passa", ao passar por mim ou em mim, deixa um vestígio, uma marca, um rastro, uma ferida. Daí que o sujeito da experiência não seja, em princípio, um sujeito ativo, um agente de sua própria experiência, mas um sujeito paciente, passional. Ou, dito de outra maneira, a experiência não se faz, mas se padece.

Colocar-se no lugar daquele que aprende, no lugar do aluno, possibilita ao educador compreender seu próprio processo de formação e coopera para uma reconfiguração dos modelos das semanas pedagógicas e reuniões escolares quando o assunto é a formação continuada.

\section{PROJETOS DE EDUCADORES: UMA EXPERIÊNCIA INTERESSANTE}

$\mathrm{Na}$ intenção de colaborar com as práticas de trabalho, uma vez que havia sido diagnosticada a necessidade de melhor conhecer novas metodologias de trabalho com o texto na escola, a secretaria municipal de educação de um município do interior do 
Paraná, no papel da secretária de educação, convidou-me ${ }^{1}$ para ministrar alguns cursos de formação com os professores da rede ao longo do ano de 2009.

$\mathrm{Na}$ época, pude constatar a dificuldade da maioria dos professores lotados nessa secretaria de colocar em prática estratégias que pudessem colaborar para as atividades de leitura e produção textual com seus alunos de maneira crítica e proficiente. Os famosos discursos, os quais já foram mencionados anteriormente, repletos de conotação negativa na postura do corpo discente, era bastante presente nesses encontros. Aos poucos e com a experiência que já possuía do trabalho com meus alunos na educação básica, e fundamentado nas teorias que acabaram se fortalecendo com meu ingresso no programa de pós-graduação em Estudos da Linguagem, no ano de 2010, pude realizar uma formação continuada com esse grupo de educadores que foi se estendendo ano a ano quando fui convidado a retornar nos encontros de semanas pedagógicas para dialogar com esses professores novamente.

Conforme o tempo foi passando, fui amadurecendo minha prática na formação desse grupo de professores, o que trouxe resultados bastante motivadores para a continuação desse processo de formação. O grupo de professores, assim como os gestores escolares daquele município foram relatando nas rodas de conversa dos encontros, um amadurecimento do grupo exemplificando suas práticas na escola. Trabalhar com o texto na sala de aula, seja para o desenvolvimento de práticas de leitura ou para a prática de escrita dos gêneros textuais começou a tomar novos sentidos para o grupo, uma vez que uma das iniciativas era a de organizar uma sequência de trabalho, já que estava ciente que as atividades com os gêneros textuais ocorriam sem a preocupação com a sequência didática.

A participação do grupo de professores nos encontros sempre foi bastante ativa e curiosa, e isto se deve muito a postura da secretária de educação que sempre procurou dialogar e negociar as datas, horários, temas e planejamentos desses encontros de formação junto com o grupo.

É válido destacar essa postura gestora, uma vez que defendo a afetividade como parte integrante da formação do professor, e considero o diálogo como uma grande manifestação de afetividade - não muito presente em alguns relacionamentos entre

\footnotetext{
${ }^{1}$ Usarei a primeira pessoa do singular por se tratar de experiência particular.
} 
gestores e docentes. Assim como acredito no diálogo nas práticas de trabalho com os alunos, também é válido com os professores, afinal falo de aprendizagem mediada pelo afeto, pelo respeito. Nessa perspectiva, defendo a ideia de Moreno e Sastre (2003, p. 131), quando apontam "a conveniência de situar no eixo central do currículo a aprendizagem das competências cognitivas, afetivas e sociais necessárias para 0 estabelecimento de relações pessoais equitativas e satisfatórias".

Por iniciativa dos próprios professores, tendo em vista o que já havíamos realizado desde o ano de 2009, recebi o convite para realizar um trabalho diferente ao longo do ano de 2014. Um trabalho mensal de acompanhamento das atividades com a Língua Portuguesa com um grupo menor de professores. Eram apenas quinze professores no início e que logo aumentou para dezoito, por adesão voluntária de mais três professoras. Esse grupo não participava das atividades do PACTO, Programa de formação de professores $^{2}$ para a alfabetização na idade certa gerido pelo governo federal, e, portanto, segundo a secretária de educação, precisavam participar de um processo de formação continuada como requisito para obterem certificação para sua elevação de nível prescrita no plano de carreira daquele município. Nada melhor, segundo a secretária de educação, "do que darmos continuidade ao trabalho que havíamos iniciado nos anos anteriores".

Sendo assim, iniciei um processo de formação continuada mensal com o grupo de educadores, ministrando oficinas que pudessem validar e revisitar tudo o que desde o ano de 2009 iniciamos naquele município. O trabalho partiu do que tenho pensado nos últimos tempos e que tem trazido resultados interessantes em minha própria prática de trabalho na educação básica, o trabalho com o letramento via projetos de ensino.

As datas para os encontros foram organizadas semestralmente com os professores e previam encontros mensais de quatro horas, todos no período noturno, conforme sugestão do grupo. Os encontros foram todos organizados de modo que os professores pudessem experimentar estratégias de trabalho e estudo que rompessem com a estrutura tradicional de uma escola em que o professor é quem mais fala e os alunos ficam sentados um de frente com o outro apenas ouvindo, anotando e fazendo

\footnotetext{
${ }^{2}$ Pacto Nacional pela Alfabetização na Idade Certa é um compromisso formal assumido pelos governos federal, do Distrito Federal, dos estados e municípios de assegurar que todas as crianças estejam alfabetizadas até os oito anos de idade, ao final do $3^{\circ}$ ano do ensino fundamental. Mais sobre em: http://pacto.mec.gov.br/o-pacto
} 
provas para avaliar o que haviam aprendido. Foi escolhida tal estratégia, a de se trabalhar com projetos, para que os professores pudessem, aos poucos, compreender o que tenho pensado sobre a organização da escola e das formas de se aprender e ensinar na atualidade, fundamentadas nas teorias atuais sobre metodologias de ensino e na minha experiência docente.

Com base em nossa experiência, minha e do grupo de professores participantes, e nos estudos que nos possibilitam pensar uma nova escola via projetos de aprendizagem, pudemos, ao longo do ano, refletir sobre práticas de letramento na instituição escolar a partir de projetos. Para isso, foi necessário revisitar algumas literaturas que pudessem nos ajudar nesse sentido. A função dos projetos é favorecer a criação de estratégias de organização dos conhecimentos escolares em relação ao tratamento das informações, e a relação entre os diferentes conteúdos em torno de problemas ou hipóteses que facilitem ao corpo discente a construção de seus conhecimentos, as transformações da informação procedente dos diferentes saberes disciplinares em conhecimento próprio (HERNÁNDEZ e VENTURA, 1998).

No que diz respeito à metodologia de projetos nos ancoramos nos autores supracitados, que trazem o currículo escolar como reflexão para o desenvolvimento das atividades escolares. Nesse sentido, ressignificamos o papel dos documentos prescritivos, dos livros didáticos, dos planejamentos e materiais de apoio do professor, que, em muitos casos, são vistos (quando vistos!) pelos professores como materiais a serem seguidos, página por página, ou apenas como um material burocrático que serve para convencer as instâncias superiores (gestores, secretários de educação e núcleos de ensino) de que o material está sendo colocado em atividade com os alunos, como é o caso dos planejamentos e currículos. Tal ressignificação permitiu ao grupo entender o papel de apoio desse material que serve para o desenvolvimento de atividades escolares e não como um material pronto, acabado.

Com olhos bastante atentos nessa perspectiva, a de utilizar os materiais prescritivos como material de apoio, passamos a melhor compreender o papel dos textos na vida do aluno na perspectiva de seu uso, de leitura e produção no universo social, buscando entender que os projetos de leitura e produção escrita não só podem como devem colaborar para o desenvolvimento de práticas sociais desses alunos colocando-os 
em situações mais próximas possíveis de seu uso real, valorizando a multiplicidade de culturas ( CANCLINI, 2008 apud ROJO, 2012).

Nesse momento é que as possibilidades de se organizar projetos de aprendizagem começaram a fazer sentido. Pudemos perceber a possibilidade de utilizar um texto poético, jornalístico, publicitário, ou textos da esfera tecnológica, como prescrito no material didático ou no planejamento, para fazer com que o aluno entenda melhor seu entorno fazendo com que a leitura e a produção desse texto tenha sentido, verdadeiramente. Assim, estaremos trabalhando com os multiletramentos que podem ou não envolver o uso de novas tecnologias de comunicação e de informação, "mas como um trabalho que parte das culturas de referência do alunado e de gêneros, mídias e linguagens por eles conhecidos, para buscar um enfoque crítico, pluralista, ético e democrático". (ROJO, 2012, p.8)

\section{AS OFICINAS - PROJETOS COM EDUCADORES}

Conforme já comentamos, as oficinas aconteciam mensalmente em um período de aproximadamente quatro horas. Procuramos eleger inúmeros tópicos que atendessem às necessidades do grupo, a partir do que levantamos como nossa pergunta de pesquisa, nossa "análise" inicial, de acordo com Leffa (2008). Nesse processo de investigação junto dos professores, surgiram inúmeros tópicos que precisavam ser melhor estudados e compreendidos pelos educadores, dentre eles os conceitos de letramento, projetos de ensino, leitura, produção de textos e uso de tecnologias na educação. Procurando criar uma ambiência de estudos com o grupo, utilizei-me das mais variadas estratégias possíveis para convidar os professores a participar dos encontros.

Havia leituras, dentre as atividades, seguidas de práticas de reflexão, elaboração de material e estratégias de ensino. Para isso, valorizamos o que Leffa (2008, p.15-16) apresenta como uma sequência de atividades e etapas para a elaboração de materiais: (1) análise, (2) desenvolvimento (3) implementação e (4) avaliação.

Utilizamos uma escola municipal como espaço para os encontros, no entanto, não somente a sala de aula foi utilizada para as propostas de trabalho, mas também os lugares disponíveis na instituição, tais como o jardim, a sala de professores e até a rua em frente à escola, que divide a zona urbana da rural. Isso foi importante para o grupo na perspectiva de entender, em nossa proposta de projetos escolares, a necessidade de se 
considerar os espaços de aprendizagem, bem como o que entendemos como comunidade de aprendizagem, pessoas físicas e jurídicas, e também instituições que possam colaborar para o processo de formação do aluno. Ou seja,

[u]ma comunidade humana que constrói um projeto educativo e cultural próprio, para educar a si mesma, as crianças, jovens e adultos, graças a um esforço endógeno, cooperativo e solidário baseado em um diagnóstico não apenas de suas carências, mas, sobretudo, de suas forças para superar suas carências. (TORRES, p. 1, s/d)

A estrutura da sala de aula também foi inúmeras vezes modificada, não por mim, coordenador dos encontros, mas pelo próprio grupo, a partir de minhas provocações, quando incitava o grupo a escolher o lugar mais agradável e confortável para se realizar determinadas atividades. Em algumas situações, o chão foi o melhor lugar, como podemos ver nas fotos a seguir, isso para quebrarmos a tradição de uma formação que necessita do grupo organizado sempre da mesma forma, carteira atrás de carteira em filas indianas.

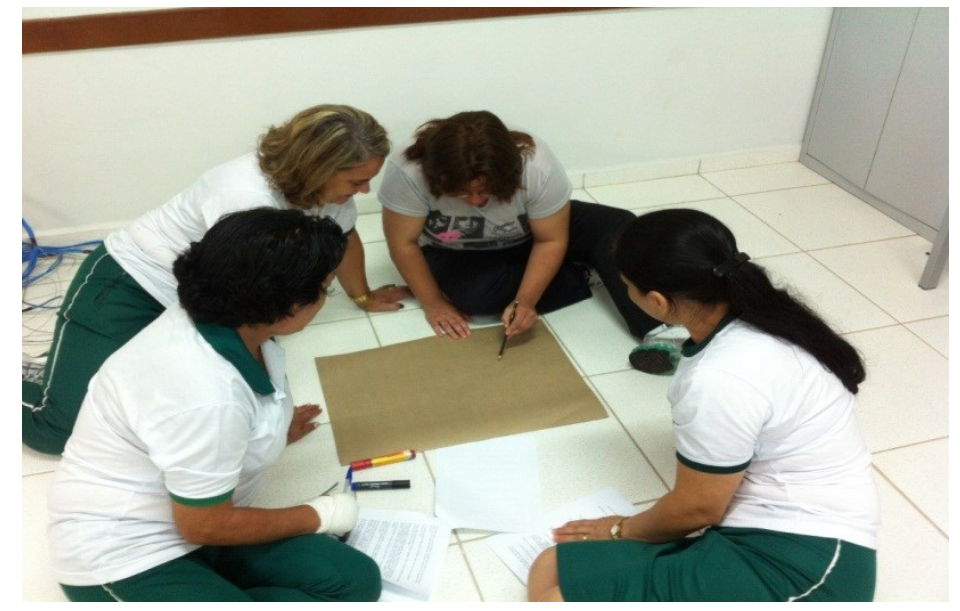

Imagem I - professores em atividades 


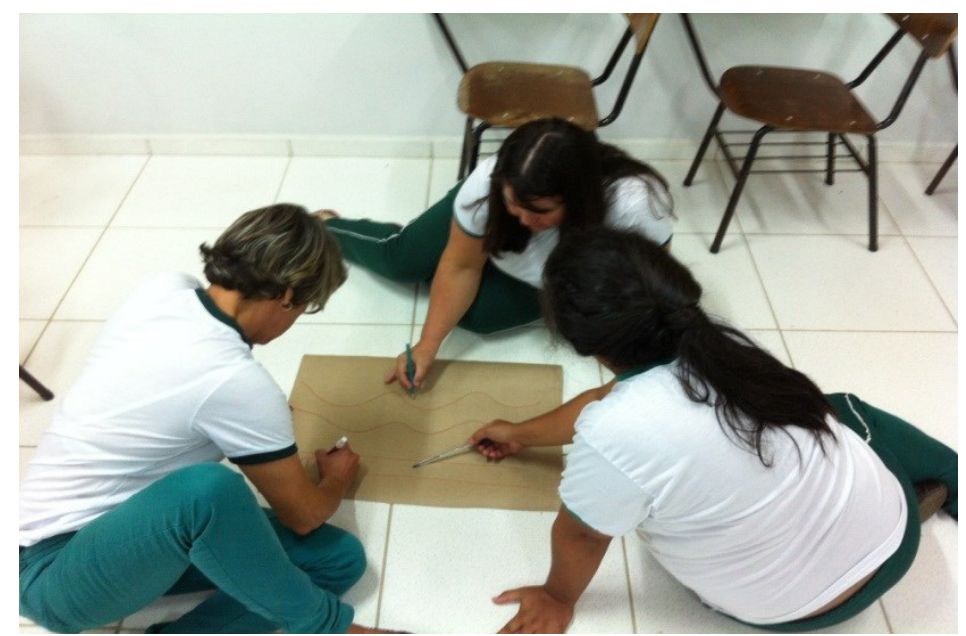

Imagem II - professores em atividade

Com o tempo, o grupo foi assimilando o grande propósito, que era o de criar um ambiente de ensino e aprendizagem a partir do qual eles pudessem realizar com espontaneidade, liberdade e autonomia e perceber que aquilo que estava acontecendo na formação de adultos profissionais, poderia ser naturalmente colocado em prática com seus alunos na sala de aula do ensino fundamental.

Leituras sobre os temas eleitos foram realizadas nas oficinas, seguidas, como já dissemos de práticas de elaboração de material didático e de estratégia de trabalho com o texto na sala de aula, seja na modalidade de leitura ou de produção escrita. Para reafirmar que os resultados foram aparecendo, pudemos notar as habilidades que o grupo foi adquirindo ao longo das oficinas. Aos poucos, pudemos perceber um significativo progresso no que diz respeito ao aproveitamento das imprevisibilidades discursivas que os alunos traziam para sala de aula. Sobre isso, Hernandez apud Tinoco (1998) aponta que a imprevisibilidade e o replanejamento das ações em seu decurso marcam verdadeiramente os projetos de trabalho escolar.

Os relatos das professoras foram deixando claro o quanto se passou a valorizar, os inúmeros textos trazidos pelos alunos às aulas. Da piada à música do momento, tudo era aproveitado para se iniciar um trabalho de compreensão da língua em uso, a Língua Portuguesa que os alunos falam, ouvem, escrevem, digitam.

Assim, cumprimos com uma de nossas metas que era a de colaborar com a ressignificação dos trabalhos com o texto na sala de aula e valorizar os multiletramentos, como nos assinala Rojo (2012, p.13), cujo conceito 
(...) aponta para dois tipos específicos e importantes de multiplicidade presente em nossas sociedades, principalmente urbanas, na contemporaneidade: a multiplicidade cultural das populações e a multiplicidade semiótica de constituição dos textos por meio dos quais ela se informa e se comunica.

Nesse sentido, muito além de se organizar aulas com o texto desprovido de sentido para o aluno que lê e escreve, as aulas puderam ser pensadas e elaboradas pelo grupo de professores participantes a partir da cultura dos alunos, daquilo que realmente interessava a eles.

Diante dessa realidade, foi proposta a elaboração de materiais didáticos pelos professores na oficina a fim de colocarmos em prática as teorias que foram estudadas ao longo dos encontros. No que concerne a análise, conforme já mencionamos, foi necessário observar o que o grupo de professores necessitava com as oficinas, quais eram seus anseios e dificuldades, o que nos levou a compreender que precisávamos pensar melhor na elaboração de materiais de trabalho com o texto na sala de aula, fundamentados nas literaturas atuais e, assim, nos propusemos realizar as atividades. Nas etapas que dizem respeito ao desenvolvimento e implementação, fizemos inúmeras atividades que puderam colocar o professor em contato direto com a elaboração de materiais revisitando teorias e práticas e valorizando a cultura local, o que surtiu inúmeros efeitos positivos com aulas melhor elaboradas.

A organização dessas atividades, dentre inúmeras outras que foram produzidas ao longo das oficinas, mostrou-nos o progresso do trabalho na formação desses professores. Inicialmente, as atividades com o texto em sala de aula eram todas realizadas seguindo os materiais que a escola possuía, ou seja, livros didáticos ou apostilas com textos e questões já elaboradas para serem respondidas. As questões eram todas de nível fácil, em sua maioria básicas, de extração de elementos óbvios explícitos, como o nome de personagem, local em que ocorria a história, personagens principais, sem uma preocupação com os elementos extratextuais e contextuais presentes no material. Vale dizer também que as atividades de produção escrita estavam todas bastante ligadas à produção da tipologia narrativa, e que raramente um gênero textual diferente da história (conto, fábula, crônica...) era sugerido como atividade.

Segundo o grupo de professores, a partir de uma melhor compreensão sobre estratégias de trabalho com a leitura e a produção de textos, o que ocorreu no processo 
de formação continuada desse grupo, é que foi possível pensar na elaboração de propostas didáticas que contemplassem não apenas o nível superficial (BARROS, 2002) dos textos, mas utilizá-los com maior profundidade, fazendo uso desse material para o início de atividades que extrapolassem o simples ler e responder às perguntas que muitas vezes já vinham prontas nos materiais didáticos.

E assim seguimos ao longo do ano de 2014. Finalizamos os trabalhos em dezembro daquele ano na certeza de que muito foi realizado durante aquele processo de formação. As construções foram significativas para todos e o mais interessante é que não somente as práticas de leitura e escrita foram ressignificadas nesse grupo, mas principalmente aquilo que tínhamos por objetivo desde o início: um repensar a prática pedagógica desse grupo por meio de projetos de trabalho. Nos relatos dos professores, em conversas posteriores, ficou bastante evidente o quanto foi significativo o processo de formação continuada nos moldes como utilizamos ao longo do ano. Considerar os momentos de formação dos professores, colocando-os em posturas semelhantes às dos alunos, possibilitou uma constante reflexão sobre as práticas pedagógicas tradicionais e as atuais. Novas posturas em salas de aula, um novo olhar para os espaços de aprendizagem, ressignificações acerca de matérias didáticos e de propostas de ensino com o texto em sala de aula apareceram pouco a pouco na avaliação dos gestores das escolas atendidas.

Hoje, as escolas do município em questão, realizam excelentes trabalhos de leitura e produção escrita por meio de projetos de trabalho, tendo como referência tudo o que foi realizado nas oficinas no ano anterior.

\section{CONSIDERAÇÕES FINAIS}

Nossa intenção nesse relato foi a de apresentar nossa experiência na formação de professores do ensino fundamental I no que tange o trabalho com o texto em sala de aula. Para isso, procuramos exemplificar o trabalho realizado em uma secretaria de educação municipal do interior do estado do Paraná no qual pudemos realizar a formação continuada dos professores envolvidos nesse programa de formação.

Inicialmente, procuramos problematizar o que entendemos por formação continuada, refletindo sobre o processo de ensino e aprendizagem de modo global, entendendo que, em muitos aspectos, aluno e professor, criança e adulto aprendem da mesma forma e isso precisa ser dialogado com os educadores. Tal diálogo proporciona 
reflexões sobre a prática pedagógica promovendo inquietações sobre as metodologias, instrumentos e motivações utilizados pelos professores no dia a dia da sala de aula.

A partir disso, defendemos nosso ponto de vista acerca da formação continuada via projetos didáticos, em que utilizamos a análise do grupo e de suas necessidades, as perguntas exploratórias para a identificação das necessidades dos educandos e o envolvimento da comunidade no desenvolvimento de um projeto educacional. Tudo isso, utilizando-se dos manuais, livros didáticos e principalmente do currículo escolar como materiais de apoio para o processo de organização de um projeto escolar. Defendemos, inclusive, a presença das imprevisibilidades durante um projeto, entendendo essas como importantes, pois são nesses momentos que os alunos trazem suas curiosidades para o espaço escolar e que podem - ou devem - ser utilizados como objetos de ensino.

Nossa experiência com adolescentes, elaborando projetos de ensino nas aulas de Língua Portuguesa e, agora, na formação de professores, nos faz compreender o que parece óbvio: é necessário repensar as metodologias de trabalho em tempos que o professor já não parece ser o único detentor do saber e que inúmeras fontes podem preencher as lacunas e curiosidades trazidas pelos alunos dessa geração curiosa e sedenta por novidades.

Valorizar a cultura linguística dos alunos, que ouvem, leem, escrevem e produzem uma grande e diversificada quantidade de gêneros textuais em suportes variados é valorizar aquilo que de curioso e interessante os alunos trazem para o espaço da escola. Diante disso, acreditamos que os discursos acerca do baixo rendimento e participação dos alunos nas atividades propostas pela escola comecem a ser discutidos em um tom mais otimista.

\section{REFERÊNCIAS}

BARROS, Diana Luz. P. Teoria do discurso - fundamentos semióticos. São Paulo: Humanitas, 2002.

HERNANDEZ, Fernando.; VENTURA, Montserrat. A organização do currículo por projetos de trabalho. 5 ed. Porto Alegre: Artmed, 1998. 
LARROSA, Jorge. Experiência e alteridade em educação. Revista Reflexão e Ação, Santa Cruz do Sul, v.19, n2, p.04-27, jul./dez. 2011.

LEFFA, Vilson. Como produzir materiais para o ensino de línguas. In: Produção de materiais de ensino: prática e teoria. 2 ed. Pelotas: Educat, 2008

MORENO, Montserrat.; SASTRE, Genoveva. O significado afetivo e cognitivo das ações. In: ARANTES, V.A. (org.) Afetividade na escola: alternativas teóricas e práticas. São Paulo: Summus, 2003.

ROJO, Roxane.; Protótipos didáticos para os multiletramentos. In: ROJO, R.; MOURA, E. Multiletramentos na escola. São Paulo: Parábola Editorial, 2012.

TINOCO, Glícia Toledo. Projetos de letramento: ação e formação de professores de língua materna. Campinas - SP - 2008

TORRES, Rosália. Maria. Comunidade de Aprendizagem: a educação em função do desenvolvimento local $\mathrm{e}$ da aprendizagem. Disponível em: http://pt.scribd.com/doc/23527865/A-educacao-em-funcao-do-desenvolvimento-local-eda-aprendizagem\#scribd. Acesso em: 06/01/2015

\section{O AUTOR}

Sergio Vale da Paixão é professor do Instituto Federal do Paraná, campus de Jacarezinho. Graduado em Letras/Inglês pela Universidade do Norte do Paraná (UENP), especialista em Ensino de Língua Inglesa (EMBRAPE), graduado em Pedagogia pela FEATI, Faculdade de Ibaiti - Pr, Mestre em Estudos da Linguagem pela UEL e Doutorando em Psicologia na UNESP, Assis - SP. É coordenador do Grupo de Pesquisa GECLIT - Ensino, Cultura, Linguagem e suas Tecnologias IFPR - Jacarezinho.

E-mail: sergiovpaixao@hotmail.com/sergio.paixao@ifpr.edu.br 